\title{
CRIMINAL COMPLIANCE ANTILAVAGEM: PREVENÇÃO PENAL POR AGENTES PRIVADOS E O DIREITO AO SILÊNCIO
}

\section{ANTI-MONEY-LAUNDERING CRIMINAL COMPLIANCE: CRIMINAL PREVENTION BY PRIVATE AGENTS AND THE RIGHT TO SILENCE}

\author{
Lauro Pinto Cardoso Neto \\ Universidade Católica de Brasília (Brasília, DF, Brasil) \\ Nefi Cordeiro \\ Universidade Católica de Brasília (Brasília, DF, Brasil) \\ José Eduardo Sabo Paes \\ Universidade Católica de Brasília (Brasília, DF, Brasil) \\ Recebimento: 5 dez. 2018 \\ Aceitação: 14 maio 2019
}

\begin{abstract}
Como citar este artigo / How to cite this article (informe a data atual de acesso / inform the current date of access):
CARDOSO NETO, Lauro Pinto; CORDEIRO, Nefi; PAES, José Eduardo Sabo. Criminal compliance antilavagem: prevenção penal por agentes privados e o direito ao silêncio. Revista da Faculdade de Direito UFPR, Curitiba, PR, Brasil, v. 64, n. 2, p. 89-110, maio/ago. 2019. ISSN 2236-7284. Disponível em: https://revistas.ufpr.br/direito/article/view/63741. Acesso $\quad$ em: 31 ago. 2019. DOI:
\end{abstract} http://dx.doi.org/10.5380/rfdufpr.v64i2.63741.

\section{RESUMO}

O artigo aborda o instituto do criminal compliance, o qual é destinado à prevenção penal, objetivando evitar a prática de crimes pelos integrantes das organizações ou por terceiros que com elas se relacionam, servir como um meio para a comunicação de um delito à autoridade competente e formar uma cultura ética motivadora de comportamentos desejáveis. Além disso, o presente trabalho tem por objetivo problematizar a aplicação do princípio constitucional do direito ao silêncio ou à não produção de prova contra si mesmo (nemo tenetur se detegere), nas investigações privadas conduzidas em programas de criminal compliance. Para melhor compreensão será discutido o tema no âmbito da prevenção de lavagem de dinheiro. Ainda serão abordadas as funções do Ministério Público. A metodologia adotada é crítico-dialética, com abordagem qualitativa, a partir do referencial teórico dos princípios constitucionais e da legislação pátria, seguindo pelo exame de conceitos extraídos do material bibliográfico da literatura nacional e estrangeira. Conclui-se que nem sempre os responsáveis pelos programas de compliance ou pelas organizações são os que praticam conduta ilícita, não havendo, em princípio, conflito de interesses na comunicação de crimes. Nesse caso, entretanto, as investigações realizadas por particulares devem atentar aos direitos e garantias constitucionais, em especial o direito ao silêncio, a fim de preservar a licitude das provas, cabendo ao Ministério Público, como fiscal da ordem jurídica, sem atribuir interesse necessariamente contraposto aos investigados, assegurar a correção das apurações.

\section{PALAVRAS-CHAVE}

Criminal compliance. Prevenção penal. Lavagem de dinheiro. Princípio nemo tenetur se detegere. Ministério Público. 


\begin{abstract}
The article addresses the adoption of compliance, which is intended for crime prevention, in other words, avoidance of criminal acts by members of organizations or by third parties that relate to them, as a means to communicate a crime to the authority and to form an ethical culture motivating desirable behaviors. In addition, the present work has the objective of problematizing the application of selfincrimination clause, in private investigations carried out by compliance officers. For a better understanding, the subject will be debated in the scope of the prevention of money laundering crime. The functions of the Prosecution Service will also be addressed. The methodology adopted is criticaldialectic, with a qualitative approach, based on the theoretical reference of the constitutional principles and the national legislation, followed by the examination of concepts extracted from bibliographical material of the national and foreign literature. It is concluded that not always those responsible for compliance programs or organizations are those who practice unlawful conduct, and there is, in principle, no conflict of interest in reporting crimes. In this case, however, investigations carried out by private individuals must pay attention to constitutional rights and guarantees, in particular the right to silence (the application of self-incrimination clause), in order to preserve the lawfulness of evidence, without assigning an interest necessarily opposed to the investigated, to ensure the correctness of the investigations.
\end{abstract}

\title{
KEYWORDS
}

Criminal compliance. Crime prevention. Money laundering. Self-incrimination clause. Prosecution Service.

\section{INTRODUÇÃO}

O que se propõe no presente artigo é analisar, à luz do ordenamento jurídico nacional, se as investigações conduzidas por entes privados e a comunicação de crimes ao Ministério Público, por meio de programas de criminal compliance, constitui ofensa ao princípio constitucional do direito ao silêncio ou à não produção de provas contra si mesmo, também conhecido como princípio nemo tenetur se detegere.

Muitas vezes a busca da verdade ou a reconstrução dos fatos pode estar em conflito com algum direito fundamental do acusado. O tema ganha relevância pela ampla disseminação de programas de compliance em todos os entes privados - em especial, programas de criminal compliance, cuja implementação é obrigatória na prevenção da lavagem de dinheiro, nos termos da Lei $n^{\circ} 9.613 / 98$.

Isso porque as entidades privadas, em suas investigações e comunicação de crimes, não podem descuidar dos direitos fundamentais das pessoas envolvidas em ilícitos e olvidar que a eficiência na persecução penal não é um valor absoluto, uma vez que o procedimento de investigação (ou processo) “[...] não é somente veículo de realização do direito penal material, mas também direito constitucional aplicado, sendo indicador da cultura política e jurídica de uma sociedade.” (DIAS NETO, 1997, p. 180). 
Assim, para desenvolver a reflexão proposta, iremos discorrer sobre o criminal compliance, com ênfase à prevenção da lavagem de dinheiro, suas origens, conceito, princípios e bases normativas, aspectos da prevenção penal realizada pelas entidades privadas, o princípio nemo tenetur se detegere, além do controle que deve exercer o Ministério Público no âmbito criminal, quando destinatário das comunicações dos crimes.

A metodologia adotada será crítico-dialética, com abordagem qualitativa, a partir do referencial teórico dos princípios constitucionais e da legislação pátria, seguindo pelo exame de conceitos extraídos de material bibliográfico da literatura nacional e estrangeira.

\section{CRIMINAL COMPLIANCE ANTILAVAGEM}

\subsection{ORIGENS E CONCEITO DE COMPLIANCE}

O termo compliance assume diferentes significados a depender de sua forma de utilização e sua conceituação como fenômeno jurídico. A literatura internacional tem buscado a definição de compliance em três diferentes aspectos: i) a fixação de um conceito universalmente válido; ii) a definição do conceito sob o aspecto organizacional e da gestão; e iii) a conceituação pelas medidas concretas de sua implementação (SAAVEDRA, 2016).

A origem da expressão compliance é comumente atribuída ao verbo inglês to comply with, referente ao cumprimento de algo imposto. Em sua literalidade, a expressão compliance pode ser definida como o ato de cumprir, de estar em conformidade e executar regulamentos internos e externos buscando mitigar o risco atrelado à reputação e ao regulatório legal (MANZI, 2008).

Pode-se distinguir o significado de compliance da simples conformidade à lei, sugerindo tratar-se de um estado dinâmico de observância legal e, portanto, estado de conformidade agregado a uma orientação de comportamento. Nesse sentido, Saavedra define compliance como:

[...] um estado dinâmico de conformidade a uma orientação normativa de comportamento com relevância jurídica por força de contrato ou lei, que é caracterizado pelo compromisso com a criação de um sistema complexo de políticas, de controles internos e de procedimentos, que demonstrem que a empresa está buscando "garantir", que se mantenha em um estado de compliance. [...] (SAAVEDRA, 2016, p. 247, grifo nosso).

Tais orientações de comportamento passam a ter relevância na medida em que são estabelecidas contratualmente, normalmente por meio de Códigos de Ética ou de Conduta, ou fixadas por lei, como no caso do compliance antilavagem, podendo seu descumprimento gerar distintas consequências jurídicas no âmbito cível, administrativo e penal. 
É interessante verificar que o ordenamento jurídico nacional passou a dispor, no âmbito do criminal compliance, de espécies com distintas formatações na prevenção de prática de infrações penais, sobressaindo o compliance antilavagem, o compliance anticorrupção e o compliance antitruste. O primeiro é de implementação obrigatória para as pessoas físicas e jurídicas indicadas em lei e os demais têm a sua adoção facultada às empresas.

Dessa forma, a falta de observância do dever de compliance antilavagem importa em imposição de sanções administrativas às pessoas físicas e jurídicas obrigadas, ao tempo em que a falta de compliance anticorrupção ou antitruste irá somente impedir a mitigação da pena de multa administrativa porventura imposta, sem prejuízo da responsabilidade penal dos dirigentes e integrantes da empresa pela prática de crimes em geral.

Diante das múltiplas abordagens do instituto, que se mostra como um fenômeno abrangente, pode-se dizer que o verdadeiro significado do compliance está contido no que ele está relacionado, considerando os riscos das atividades da organização e dos atos de todos os seus participantes.

Lima define o compliance, para efeito da legislação antilavagem, como:

[...] o conjunto de regras jurídicas que impõe aos sujeitos expressamente nelas elencados duas obrigações em essência: I) a de instituir filtros em suas atividades cotidianas, consistentes em controles sobre movimentação financeira, de bens e serviços, de seus clientes, funcionários e sócios, de modo a perceber indícios do uso de sua profissão ou indústria para a transformação de bens econômicos de origem ilícita em bens econômicos aparentemente lícitos; II) a de comunicar às autoridades responsáveis a ocorrência desses indícios. (LIMA, 2013, p. 61, grifo nosso).

Destaca-se, portanto, o caráter preventivo contra a ocorrência de infrações penais ao considerar o quadro normativo, a capacidade de retorno ao ambiente de normalidade e legalidade, caso haja violação de regras, e o estabelecimento de uma cultura ética motivadora de comportamentos desejáveis aos fins da organização.

\subsection{A LAVAGEM DE DINHEIRO}

A lavagem de dinheiro é o processo que tem por objetivo disfarçar a origem criminosa dos proveitos do crime ${ }^{1}$. Um outro conceito possível é “[...] o processo pelo qual os ativos de origem criminosa são integrados ao sistema econômico legal com aparência de terem sido obtidos de maneira

\footnotetext{
1 "Money laundering is the processing of these criminal proceeds to disguise their illegal origin. This process is of critical importance, as it enables the criminal to enjoy these profits without jeopardising their source”. The Financial Action Task Force (FATF) ou Le Groupe d'action financière (GAFI). Disponível em: https://bit.ly/258f5kx. Acesso em: 4 out. 2018.
} 
legal.”2 (CORDERO, 2002, p. 93, tradução nossa). Trata-se de conduta ilícita para introdução de recursos obtidos criminosamente no sistema econômico e financeiro oficial de modo a "lavar" ou “branquear” o dinheiro “sujo”, conferindo-lhe, por conseguinte, aparência legal (VIEIRA, 2018).

O crime de lavagem de dinheiro, em seu nascimento, esteve associado a grupos terroristas na Itália e ao tráfico de drogas nos Estados Unidos, crimes considerados graves. "Parte dessa ligação é inevitável, em razão de sua estrutura típica: é um crime que remete a um crime anterior, é um metacrime.” (DE CARLI, 2012, p. 199-200, grifo do autor).

A expressão lavagem de dinheiro surgiu quando autoridades norte-americanas descreveram um dos métodos usados pela máfia para justificar a origem de recursos ilícitos: a exploração de máquinas de lavar roupas automáticas. O termo foi utilizado nos EUA em um processo judicial em 1982 e desde então passou a ser comumente utilizado na doutrina e em normas (BOTTINI, 2016a).

Para melhor compreensão de como se desenvolve a lavagem de capitais, o modelo mais utilizado é o do FATF/GAFI, que divide o processo em três fases: colocação (placement), estratificação (layering) e integração (integration). Essas fases podem ocorrer sequencialmente ou simultaneamente. Com efeito:

\begin{abstract}
Na fase inicial ou de colocação do branqueamento de capitais, o branqueador introduz os seus lucros ilegais no sistema financeiro. Isso pode ser feito dividindo-se grandes quantias em porções menores, menos visíveis, que são então depositadas diretamente em uma conta bancária ou usadas para comprar uma série de instrumentos monetários (cheques, ordens de pagamento, etc.), os quais são coletados e depositados em contas de outro local.

Depois que os fundos entraram no sistema financeiro, ocorre o segundo estágio - ou estágio de camadas. Nesta fase, o lavador se envolve em uma série de conversões ou movimentos dos fundos para distanciá-los de sua fonte. Os fundos podem ser canalizados por meio da compra e venda de papéis de investimento, ou o branqueador pode simplesmente transferir os fundos por meio de uma série de contas em vários bancos em todo o mundo. Este uso de contas amplamente espalhadas para lavagem é especialmente prevalente nas jurisdições que não cooperam em investigações contra lavagem de dinheiro. Em alguns casos, o branqueador pode disfarçar as transferências como pagamentos de bens ou serviços, dando-lhes uma aparência legítima.

Tendo processado com sucesso seus lucros criminais por meio das duas primeiras fases, o lavador então os move para a terceira fase - integração -, na qual os fundos voltam a entrar na economia legítima. O lavador pode optar por investir os fundos em imóveis, ativos de luxo ou empreendimentos comerciais ${ }^{3}$. (tradução nossa).
\end{abstract}

\footnotetext{
2 “El processo em virtude del cual los bienes de origen delictivo se integram em el sistema económico legal com aparência de aber sido obtenidos de forma lícita"

3 "In the initial - or placement - stage of money laundering, the launderer introduces his illegal profits into the financial system. This might be done by breaking up large amounts of cash into less conspicuous smaller sums that are then deposited directly into a bank account, or by purchasing a series of monetary instruments (cheques, money orders, etc.) that are then collected and deposited into accounts at another location.

After the funds have entered the financial system, the second - or layering - stage takes place. In this phase, the launderer engages in a series of conversions or movements of the funds to distance them from their source. The funds might be channelled through the purchase and sales of investment instruments, or the launderer might simply wire the funds through a series of accounts at various banks across the globe. This use of widely scattered accounts for laundering is especially
} 
Em outras palavras, a lavagem de dinheiro depura o dinheiro "sujo" em dinheiro "limpo". Em sua essência, separa-se o dinheiro de sua fonte (crime antecedente), movimenta-se o maior número de vezes possível por meio de interpostas pessoas ("laranjas” ou "testas de ferro”), distanciando-o de sua origem para, ao final, reinvestir os recursos em atividades econômicas consideradas lícitas, fazendo parecer inteiramente legítimas as operações (DE CARLI, 2012).

Basicamente, a lavagem de dinheiro é feita por três vias principais: i) movimentação física do dinheiro em espécie; ii) uso do sistema financeiro; iii) comércio internacional. A atual preocupação dos países está no controle do sistema financeiro internacional, deixando a desejar os controles estatais do comércio internacional e as transferências físicas de dinheiro (DE CARLI, 2012).

No plano internacional, os tratados de uma forma geral (Convenção de Viena, Convenção de Estrasburgo, Convenção de Varsóvia, Convenção de Palermo e Convenção de Mérida, por exemplo) impõem aos Estados-Parte a obrigação jurídica de instituir tipos penais dolosos de lavagem de dinheiro: i) o primeiro, referente à conduta de converter ou transferir bens com pleno conhecimento de que são produtos de crime e com o propósito de ocultar ou dissimular a origem ilícita desses bens ou, ainda, auxiliar pessoas na prática desses atos; ii) o segundo, relacionado à conduta de ocultar ou dissimular a verdadeira natureza, origem, localização, disposição, movimentação ou propriedade de bens de origem ilícita; iii) a aquisição, posse ou utilização de bens, sabendo aquele que os adquire, possui ou utiliza, que são produto de crime; iv) a participação na prática de crimes de lavagem de dinheiro anteriormente descritos, bem como qualquer forma de associação, acordo, tentativa ou cumplicidade, prestação de assistência ou qualquer tipo de ajuda física ou moral à sua prática (DE CARLI, 2012).

Como vimos, a lavagem de dinheiro decorre de uma anterior prática de crime, do qual origina-se o recurso ilícito, e inicia-se com a ocultação desse recurso auferido. Desenvolve-se em outras operações para dissimulação de origem dos bens e completa-se com a reinserção dos valores em atividade econômica aparentemente lícita.

No entanto, a legislação brasileira (Lei no 9.613/98), em sua tipificação penal, não exige que seja concluído todo o ciclo descrito, com a integração dos recursos ilícitos à economia lícita. Para a consumação do crime, basta a primeira fase de ocultação, cuja pena é a mesma aplicável à

prevalent in those jurisdictions that do not co-operate in anti-money laundering investigations. In some instances, the launderer might disguise the transfers as payments for goods or services, thus giving them a legitimate appearance.

Having successfully processed his criminal profits through the first two phases the launderer then moves them to the third stage - integration - in which the funds re-enter the legitimate economy. The launderer might choose to invest the funds into real estate, luxury assets, or business ventures.” The Financial Action Task Force (FATF) ou Le Groupe d'action financière (GAFI). Disponível em: https://bit.ly/258f5kx. Acesso em: 4 out. 2018. 
dissimulação e à integração. As fases da lavagem de dinheiro, como dito, desenvolvem-se sucessivamente ou simultaneamente: “[...] ainda que no plano objetivo seja suficiente a mera ocultação dos bens para a caracterização da lavagem de dinheiro, na esfera subjetiva sempre será necessária a intenção de reciclar os bens, o desejo de completar o ciclo de reciclagem [...]” (BOTTINI, 2016a, p. 33).

Merece destaque a discussão doutrinária sobre o bem jurídico protegido pela lei de lavagem de dinheiro: i) o bem jurídico lesado no crime antecedente; ii) a administração da justiça; iii) a ordem econômica; iv) a administração da justiça e a ordem econômica (pluriofensivo). Sabemos que “[...] bens jurídicos são dadas circunstâncias ou propósitos que são úteis para o indivíduo e seu livre desenvolvimento dentro da estrutura de um sistema social global estruturado com base nessa concepção dos fins ou para o funcionamento do próprio sistema.”“ (ROXIN, 2006, p. 56, tradução nossa).

Welter (2013) considera que a legislação brasileira pune a lavagem de dinheiro, protegendo bem jurídico próprio, em razão do tipo penal autônomo em relação ao crime antecedente. Ele entende haver proteção da ordem socioeconômica, assegurando a lisura das relações econômicas e impedindo a utilização de recursos ilícitos, assim como a administração da justiça, tendo em vista o interesse do Estado na apuração dos crimes cujo proveito econômico é ocultado. Já Bottini (2016c, p. 89) defende que a nossa legislação protege unicamente a administração da justiça.

Sob qualquer ângulo de verificação do bem jurídico, a penalização da lavagem de dinheiro constitui um instrumento de combate à macrocriminalidade, na medida em que busca impedir o uso dos recursos ilícitos obtidos. E as dificuldades de detecção e investigação da lavagem de dinheiro, que normalmente ocorre de maneira oculta ou dissimulada em conjunto com a prática de outros crimes, acabaram por impor às entidades privadas os deveres de prevenir e detectar ações voltadas ao referido delito, com a implantação do compliance.

\subsection{PRINCÍPIOS E BASES NORMATIVAS DO CRIMINAL COMPLIANCE ANTILAVAGEM}

O tema criminal compliance, no contexto das medidas preventivas de lavagem de dinheiro, tem como principal gestor o Grupo de Ação Financeira (GAFI), em inglês conhecido como Financial

\footnotetext{
4 “[...] los bienes jurídicos son circunstancias dadas as finalidades que son utiles para el individuo e su libre desarrollo en el marco de un sistema social global estructurado sobre la base de esa concepción de los fines o para el funcionamento del próprio sistema.”
} 
Action Task Force (FATF), constituído em 1989 pelo G755 (VERÍSSIMO, 2017). Inclusive o Brasil é integrante do GAFI, organismo que tem como objetivo principal a implementação de políticas voltadas ao combate à lavagem de dinheiro, ao financiamento do terrorismo e a outras ameaças contra a integridade do sistema financeiro internacional ${ }^{6}$. A orientação é de implantar obrigatoriamente os programas de compliance no sistema financeiro de todos os países participantes do GAFI.

No âmbito nacional, Lima e Martinez (2018) consideram que o compliance bancário nasceu efetivamente em 1998, quando foi editada a Lei de Lavagem de Dinheiro (Lei n ${ }^{\circ}$ 9.613/98), ganhando o instituto maior destaque e conhecimento público com a publicação da Lei Anticorrupção (Lei ${ }^{0}$ 12.846/2013).

A obrigatoriedade de desenvolvimento e implementação de programas de compliance antilavagem encontra-se expressamente prevista no art. 10, III, da Lei $n^{0}$ 9.613/98, que “[...] passou a exigir de determinadas empresas e profissionais que adotem 'políticas, procedimentos e controles internos’ [...], tornando assim obrigatório o desenvolvimento e implementação de programas de compliance.” (BOTTINI, 2016b, p. 53).

Consoante os arts. 10 e 11 da Lei $n^{0}$ 9.613/98, pessoas físicas e jurídicas ${ }^{7}$ elencadas no art. $9^{\circ}$ ficaram obrigadas à identificação de clientes e manutenção de cadastros, ao registro das transações, adoção de políticas, procedimentos e controles internos compatíveis com o volume de operações, a manter seus cadastros atualizados e à comunicação de operações suspeitas ou de transações financeiras de um determinado valor, definido previamente, à unidade de inteligência financeira, o Conselho de Controle de Atividades Financeiras (Coaf), órgão também criado com a finalidade de disciplinar, aplicar penas administrativas, receber, examinar e identificar as ocorrências suspeitas de lavagem de dinheiro.

A Lei de Lavagem de Dinheiro previu que indicação da forma e do procedimento para o cumprimento dessas obrigações seria de responsabilidade dos órgãos reguladores próprios e, na

\footnotetext{
${ }^{5}$ Grupo internacional composto por Alemanha, Canadá, Estados Unidos, França, Itália, Japão e Reino Unido, os quais são considerados as economias mais avançadas do mundo, segundo o Fundo Monetário Internacional (FMI).

${ }^{6}$ Maiores informações sobre o GAFI estão disponíveis em: https://bit.ly/2FdFG6I. Acesso em: 10 jun. 2018.

${ }^{7}$ Ainda segundo Veríssimo (2017), “[... juntas comerciais e registros públicos; pessoas físicas ou jurídicas que prestem, mesmo que eventualmente, serviços de assessoria, consultoria, contadoria, auditoria, aconselhamento ou assistência, de qualquer natureza, em operações de compra e venda de imóveis ou participações societárias, de gestão de fundos, valores mobiliários ou outros ativos, de abertura ou gestão de contas bancárias, de poupança, investimento ou de valores mobiliários, de criação, exploração ou gestão de sociedades de qualquer natureza, financeiras, societárias ou imobiliárias, de alienação ou aquisição de direitos sobre contratos relacionados a atividades desportivas ou artísticas profissionais, pessoas físicas ou jurídicas que atuem na promoção, intermediação, comercialização, agenciamento ou negociação de direitos de transferência de atletas, artistas ou feiras, exposições ou eventos similares; empresas de transporte e guarda de valores; pessoas físicas ou jurídicas que comercializem bens de alto valor de origem rural ou animal ou intermedeiem sua comercialização, todas estão obrigadas pela lei, à adoção de medidas de compliance, em maior ou menor extensão [...]”.
} 
ausência deste, do Coaf (art. 14, $\S 1^{\circ}$ ), variando de acordo com as atividades desenvolvidas e a complexidade das operações (BOTTINI, 2016c, p. 59-60).

Após a referida lei de lavagem, foram editadas, no âmbito do sistema financeiro nacional, a Resolução n 2.554/98 do Conselho Monetário Nacional (CMN), que instituiu as funções de controle no sistema bancário após a lei anticorrupção, e a Resolução nº 4.595/2017 do Banco Central do Brasil (Bacen), dedicada exclusivamente à política de conformidade.

Ainda podem-se citar, como normas infralegais de criminal compliance antilavagem, os seguintes normativos: i) a Circular n ${ }^{0} 3.461 / 2009$ do Banco Central do Brasil, que consolida os procedimentos a serem adotados pelas instituições financeiras e demais instituições por ele autorizadas a funcionar; ii) a Instrução n 301/99 da Comissão de Valores Mobiliários (CVM), que faz o mesmo que o Bacen em relação às pessoas sob sua fiscalização; iii) a Circular n ${ }^{\circ}$ 445/2012 da Superintendência de Seguros Privados (Susep), que dispõe sobre os controles internos a serem adotados no mercado de seguros; iv) a Resolução n 24/2013 do Conselho de Controle de Atividades Financeiras, que dispõe sobre os procedimentos às pessoas não submetidas a outro órgão regulador; v) a Instrução nº 18/2014 da Superintendência Nacional de Previdência Complementar (Previc), que cuida de orientações e procedimentos a serem adotados pelas entidades fechadas de previdência complementar ${ }^{8}$.

Em acréscimo ao rol mencionado, destacam-se: i) a Circular nº 3.654/2013 do Banco Central do Brasil, que normatiza práticas de cadastro e sistematização de informações e procedimentos para comunicação de operações suspeitas ao Coaf; ii) a Carta Circular n ${ }^{0}$ 3.542/2012, também do Banco Central do Brasil, que detalha exemplos de operações e atividades que podem configurar crime de lavagem de dinheiro; iii) a Carta Circular 3.342/2008, igualmente do Banco Central do Brasil, que dispõe sobre a comunicação de movimentações financeiras ligadas ao terrorismo e ao seu financiamento, relacionando pessoas e entidades cujas operações são suspeitas de ligação com o financiamento do terrorismo.

Não há dúvidas de que o programa de compliance auxilia as instituições financeiras na gestão de riscos, notadamente quanto à prática de crimes no seu ambiente corporativo e no sistema financeiro:

[...] Os supervisores bancários devem estar convencidos de que as políticas e procedimentos de conformidade eficazes são seguidos e que a gerência adota as ações corretivas apropriadas quando as violações das leis, regras e padrões são identificadas.

[...] Um banco deve manter padrões elevados quando estiver conduzindo seus negócios e sempre esforçar-se para observar o sentido tão bem quanto a literalidade da lei. A falha em

\footnotetext{
${ }^{8}$ Os normativos encontram-se disponíveis em: https://bit.ly/2TkjQHt. Acesso em: 10 jun. 2018.
} 
considerar o impacto de suas ações em seus acionistas, clientes, funcionários e os mercados pode resultar em significativos danos às suas imagem e reputação, mesmo quando não haja violação à lei.

A expressão "risco de compliance" é definida nesse documento como um risco de sanções legais ou regulamentares, perda financeira ou perda de reputação que um banco pode sofrer como resultado de sua falha em cumprir as leis, regulamentos, regras, padrões de boas práticas e organização e códigos de conduta aplicáveis às suas atividades bancárias (juntos, “cumprir leis, regras e padrões”).

Leis de compliance, regras e padrões geralmente cobrem assuntos como a observância de padrões apropriados de conduta de mercado, gerenciamento de conflitos de interesse, tratamento justo dos clientes e garantia da adequação de aconselhamento ao cliente. Tipicamente, incluem áreas específicas, como a prevenção de lavagem de dinheiro e o financiamento ao terrorismo, e podem estender-se a leis tributárias que são relevantes para a estruturação de produtos bancários ou aconselhamento ao cliente. [... $]^{9}$ (tradução nossa).

\subsection{O MINISTÉRIO PÚBLICO COMO INSTITUIÇÃO E AGENTE NO COMPLIANCE ANTILAVAGEM}

Nos termos da Constituição Federal, art. 127, caput, o Ministério Público é uma instituição permanente, essencial à função jurisdicional do Estado, incumbindo-lhe a defesa da ordem jurídica, do regime democrático e dos interesses sociais e individuais indisponíveis. Suas funções somente podem ser exercidas por membros da carreira, admitidos por concurso público de provas e títulos (art. 129 , $\S \S 2^{\circ}$ e $3^{\circ}$ ), com seus procuradores-gerais obrigatoriamente oriundos da carreira (art. 128). O Ministério Público é dotado de autonomia funcional, administrativa, financeira e orçamentária, e possui iniciativa legislativa (art. 127, $\S \S 2^{\circ}$ e $3^{\circ}$ ). São princípios institucionais do Ministério Público a unidade, a indivisibilidade e a independência funcional (art. 127, §1 ${ }^{\circ}$ ), e atribuiu-se a ele a competência privativa da ação penal pública (art. 129, I), admitindo-se a ação privada nos crimes de ação penal pública, quando essa não for intentada no prazo legal (art. 5², LIX). O órgão é dotado de poder de requisição e de controle externo da atividade policial (art. 229, VI a VIII, CF), decorrendo o monopólio da postulação judicial das medidas incidentes e cautelares (acessorium sequitur

\footnotetext{
9 “[...] Banking supervisor must be satisfied that compliance policies and procedures are followed and that management takes appropriate corrective action when compliance failures are identified.

[...] A bank should hold itself to high standards when carrying on business, and at all times strive to observe the spirit as well as the letter of the law. Failure to consider the impact of its actions on its shareholders, customers, employees ande the markets may result in sgnificant adverse publicity and reputational damage, even if no law has been broken.

The expression "compliance risk" is defined in theis paper as the risk of legal or regulatory sanctions, material financial loss, or loss to reputation a bank may suffer as a result of its failure to comply with laws, regulations, rules, related sefregulatory organisation standards, and codes of conduct applicable to its banking activities (together, "compliance laws, rules and satandards).

Compliance laws, rules and standards generally cover matters such as observing proper standards of market conduct, managing conflicts of interest, treating customers fairly, and ensuring the suitability of customer advice. They tipiclly include specific areas such as the prevention of money laundering and terrorist financing, and may extend to taw laws thar are relevant to the structuring of banking products or customer advice [...]”. BIS - Bank for International Settelments - Compliance and the Compliance Function in Banks, Basle Committee on Banking Supervision, April, 2005. Disponível em: https://bit.ly/2YxUhc0. Acesso em: 12 nov. 2018.
} 
principalis), assim como o controle do inquérito policial, sob o princípio acusatório do processo penal (MARTINS JUNIOR, 2015, p. 111).

A Constituição Federal de 1988 reconfigurou fortemente o Ministério Público. Foram instituídos mandatos aos procuradores-gerais e atribuídas características típicas de um Poder de Estado, a saber, autonomia institucional e independência funcional de seus membros, investidos com as mesmas garantias da magistratura judicial. Ambas as magistraturas, judicial e requerente, passaram a ter missão substancialmente idêntica e objetiva de realização da justiça (FERREIRA, 1986, p. 40).

À vista de suas atribuições, duas são as posições processuais clássicas do Ministério Público na persecução penal: a de parte - típica do modelo empírico-primitivo - e a de custos legis (RIBEIRO, 2003). A qualificação de parte ${ }^{10}$ tem sido bastante questionada. Em verdade, os membros do Ministério Público exercem a magistratura requerente, com dever objetivo de realização da justiça e do bem-estar social, observando em qualquer hipótese as garantias e os direitos das pessoas envolvidas. Diz-se que “[...] o membro do Ministério Público não é um juiz, porque não pode ditar sentenças com força de coisa julgada, mas a sua atuação e atividade correspondem à do juiz qualitativamente, na medida em que é orientado, da mesma maneira, para o valor jurídico” (ROXIN, 1993, p. 45).

Com esse entendimento, no âmbito do compliance, o Ministério Público deve assegurar os interesses sociais com objetividade e comprometer-se igualmente com os direitos individuais de todos os envolvidos, eis que não possui necessariamente um interesse contraposto ao do investigado ou réu e não é movido pelo sentimento da vítima (RIBEIRO, 2003).

\section{ASPECTOS DA PREVENÇÃO PENAL POR AGENTES PRIVADOS}

Compliance pode ser considerado um processo de privatização da prevenção do delito e do controle da criminalidade por meio de "sistemas autorreferenciais de autorregulação regulada" (SIEBER, 2001, p. 291). A instituição de programas de compliance deveu-se ao entendimento de não possuir o Estado capacidade fiscalizatória suficiente em todos os ambientes econômicos e corporativos, necessitando da cooperação dos entes privados para a prevenção de crimes, fixando em

\footnotetext{
${ }^{10}$ Nos termos do atual Código de Processo Penal português (Lei nº 59/98): “Ao Ministério Público é deferida a titularidade e a direção do inquérito, bem como a competência exclusiva para a promoção processual: daí lhe seja atribuído, não o estatuto de parte, mas de uma autêntica magistratura, sujeita ao estrito dever de objetividade” (ANTUNES, 1998). De igual modo, o membro do Ministério Público no processo penal alemão não é considerado parte, uma vez que tem que reunir provas e investigar a verdade dos fatos, bem como pode interpor recursos ou propor revisão criminal para a absolvição do condenado, visando em todos os casos de sua atuação uma decisão judicial correta (ROXIN, 2000, p. 53).
} 
contrapartida, por conseguinte, a extinção ou redução de sanções estatais dos que efetivamente colaborarem segundo regras previamente estabelecidas (SIEBER, 2001).

A adoção do compliance também pode ser entendida como decorrência de uma sociedade de risco, que no dizer de Beck (2010) se vê confrontada consigo mesma:

[...] em contraste com todas as épocas anteriores (incluindo a sociedade industrial), marcada fundamentalmente por uma carência: pela impossibilidade de imputar externamente as situações de perigo. À diferença de todas as culturas e fases de desenvolvimento social anteriores, que se viam confrontadas a ameaças das mais variadas formas, atualmente a sociedade se vê, ao lidar com riscos, confrontada consigo mesma. Riscos são um produto histórico, a imagem especular de ações e omissões humanas, expressão de forças produtivas altamente desenvolvidas. Nessa medida, com a sociedade de risco, a autogeração das condições sociais de vida torna-se problema e tema (de início, negativamente), na demanda pelo afastamento dos perigos. (BECK, 2010, p. 275, grifo nosso).

Sob o aspecto econômico, a prática de crimes tem as seguintes premissas: i) a obediência à lei não está garantida; ii) os recursos públicos e privados que são utilizados para prevenção não consideram a perda social como referência aos gastos ou alocações desses recursos, seja como critérios de dissuasão, retribuição, compensação ou reabilitação (BECKER, 1968). A perda social, potencial ou efetivamente ocorrida, pode ser medida para a implantação do compliance pelas entidades privadas, as quais são chamadas, por meio da regulação estatal, a colaborar com a prevenção de ilícitos. A utilidade esperada, nesse caso, será a melhoria do comportamento ético-empresarial, da concorrência, da governança, da reputação, da responsabilidade social.

Entretanto, não obstante o esforço empreendido, deve-se considerar que o criminal compliance não tem por objetivo eliminar completamente o risco da prática de crimes de lavagem de dinheiro por meio das instituições financeiras, tendo em vista a possibilidade de agentes de má-fé encontrarem meios e forma de evitar o monitoramento.

A finalidade precípua das políticas de prevenção é a implementação de padrões de conduta, que reduzam o risco da ocorrência de delitos a um patamar mínimo tolerável, e que possa facilitar a atuação de outras autoridades de investigação diante dos indícios revelados (BOTTINI, 2016c, p. 55). Obviamente " [...] todo mecanismo de control tiene limitaciones inherentes que no pueden impedir que algunas vulneraciones no se prevengan o detecten, normalmente debido a errores humanos, negligencia o dolo” (YSLA, 2012, p. 87).

Nos casos de implementação facultativa do compliance, mediante compartilhamento da responsabilidade pelas investigações que ocorrem em seu ambiente organizacional, o Estado tem oferecido mecanismos de incentivo à colaboração e à comunicação de crimes. Assim: 
[..] a admissão de determinados deveres a serem suportados pelos agentes e empresas atuantes no mercado financeiro e econômico está intimamente ligada aos esforços envidados para se prevenir o delito de lavagem de capitais. [...] Em outras palavras, o Estado, para evitar a prática do delito em questão, acaba por determinar que certas pessoas ou empresas assumam determinados ônus da prática de suas atividades (suportar o risco e cumprimento dos deveres estabelecidos pelas boas práticas negociais) e também, permitir, com a prevenção ex ante do delito de lavagem de capitais, que os bens ou valores decorrentes de uma prática delitiva anterior sejam mais facilmente recuperados e a prova do delito seja mais fácil, uma vez que não conta com o processo de camuflagem introduzido pelo branqueamento de capitais. Em suma, parece facilmente constatável a estreita relação entre os esforços estatais e internacionais em prol do combate ao delito de lavagem de dinheiro e o estabelecimento do criminal compliance (GLOECKNER; DA SILVA, 2014, p. 153-154).

Os programas de compliance no direito comparado seguem a mesma lógica em admitir contrapartida ao esforço gerado, chegando a ponto de afastar a própria responsabilidade penal em alguns casos, como é o caso do Bribery Act, da legislação inglesa, em relação à pessoa jurídica:

Uma organização comercial será suscetível à persecução penal se uma pessoa a ela associada subornar uma outra pessoa no intuito de obter ou reter negócios ou uma vantagem na condução de negócios para aquela organização. Como disposto acima, a organização comercial terá uma "defesa integral” se mostrar que, a despeito de um caso particular de suborno, ela dispunha de procedimentos adequados para a prevenção de suborno por parte das pessoas a si associadas. De acordo com precedentes estabelecidos, o padrão de provas que a organização comercial precisaria desqualificar para construir sua defesa, na ocasião de sua imputação, é o juízo de probabilidade ${ }^{11}$ (REINO UNIDO, 2010, p. 15, tradução nossa).

Ademais, a adoção do compliance pode agregar valor positivo e vantagem competitiva, pela demonstração de confiabilidade e integridade, não obstante eventual nível de engessamento negocial com o atrelamento às boas práticas (BOTTINI, 2016c).

No Brasil, como dito anteriormente, o criminal compliance antilavagem é de implementação obrigatória por força da Lei ${ }^{\circ}$ 9.613/98. Convenções internacionais fixaram o entendimento de que a tarefa de prevenir e apurar prática de crimes não são tarefas exclusivas dos Estados. Conforme Veríssimo (2017, p. 13):

[...] as empresas são chamadas a atuar, elaborando códigos de ética e desenvolvendo programas de compliance destinados a promover o adequado cumprimento das normas por parte de seus órgãos, devem investigar as irregularidades praticadas, adotar medidas corretivas e, quando for o caso, entregar os resultados às autoridades competentes [...].

Trata-se, portanto, em sua essência, de uma gestão de riscos de persecução penal:

\footnotetext{
11 “A commercial organisation will be liable to prosecution if a person associated with it bribes another person intending to obtain or retain business or an advantage in the conduct of business for that organisation. As set out above, the commercial organisation will have a full defence if it can show that despite a particular case of bribery it nevertheless had adequate procedures in place to prevent persons associated with it from bribing. In accordance with established case law, the standard of proof which the commercial organisation would need to discharge in order to prove the defence, in the event it was prosecuted, is the balance of probabilities.”
} 
[...] o criminal compliance procura evitar a responsabilização de agentes ou da empresa que opere com o mercado financeiro, determinando procedimentos para que, com seu cumprimento, seja evitada uma prática delitiva. O que se promove com esta estratégia de governança corporativa é a gestão de riscos de persecução penal através de procedimentos padronizados e que, portanto, possam ser controlados por uma agência fiscalizatória (compliance officer) [...] (GLOECKNER; DA SILVA, 2014, p. 151, grifo nosso).

Como vimos, o Estado, por meio de instrumentos regulatórios, pode transferir parte dos custos públicos de fiscalização e prevenção de ilícitos, adotando, nesses casos, uma política de incentivos, benefícios e contrapartidas, para adoção do programa por parte das entidades privadas. A questão que merece reflexão é a observância a garantias e direitos fundamentais às investigações privadas do programa de compliance, em especial o direito ao silêncio e ao de não produzir prova contra si mesmo.

\section{A COMUNICAÇÃO DE CRIMES E O PRINCÍPIO NEMO TENETUR SE DETEGERE.}

Um programa de compliance busca garantir o cumprimento das leis e normas em geral por todos os seus integrantes e, em caso de inobservância ou de prática de algum ilícito, possibilita a sua descoberta e a aplicação da sanção correspondente, inclusive com a comunicação do fato a outro órgão ou à autoridade competente. O criminal compliance, além dos riscos do negócio, também se ocupa dos riscos pessoais dos dirigentes e administradores das organizações, ensejando a comunicação ao Ministério Público.

Para uma melhor abordagem da garantia do direito ao silêncio e à não produção de provas contra si mesmo, utilizaremos o instituto do criminal compliance antilavagem, devido à sua natureza obrigatória, embora a controvérsia seja pertinente aos demais programas.

Com efeito, alinhando-se a normativos internacionais, o legislador brasileiro fixou regras de cooperação privada ao enfrentamento da lavagem de dinheiro (Lei $n^{\circ}$ 9.613/98). Aqueles que atuam em setores considerados vulneráveis à prática de crime passam a ter obrigações de: i) guardar informações de usuários dos serviços; ii) informar atividades suspeitas de lavagem de dinheiro; iii) instituir sistema de compliance, principalmente para o cumprimento das normas impostas (BOTTINI, 2016b).

Como críticos a essas investigações e comunicações de crimes, Gloeckner e Da Silva (2014, p. 147-172) sustentam que a implementação dos deveres de compliance da Lei de Lavagem de Dinheiro é responsável pelo enfraquecimento do princípio fundamental do nemo tenetur se detegere, consistente na vedação, ao Estado, de obtenção de provas contra a vontade do suspeito ou do acusado. 
Os referidos autores sustentam não ser possível conciliar os deveres de compliance, com cominação de sanções administrativas em caso de descumprimento, e o direito de não produzir prova contra si mesmo, conforme o brocardo nemo tenetur se detegere. Sustentam que o sistema acusatório vigente no processo penal exige que a iniciativa e a responsabilidade probatória encontrem-se com as partes, no caso o Ministério Público (princípio do dispositivo), prevalecendo a garantia de não se exigir a cooperação do acusado com o órgão de acusação (GLOECKNER; DA SILVA, 2014, p. 156157).

Os autores defendem, ainda, que há grave violação ao princípio nemo tenetur se detegere na hipótese de pessoas com o encargo dos deveres de compliance, as quais podem sofrer sanções administrativas em caso de descumprimento normativo, serem consideradas suspeitas ou acusadas de prática do delito de lavagem de dinheiro (GLOECKNER; DA SILVA, 2014, p. 159).

Por essas e outras razões a adoção de programas de compliance sempre foi vista com reservas:

\begin{abstract}
A implementação de políticas de compliance foi vista com reservas por profissionais e empresas durante muito tempo - e ainda o é, de certa forma - por alguns motivos. Um deles é o paradoxo que a estrutura carrega consigo, uma vez que ao buscar uma redução de responsabilidades administrativas e penais, um sistema eficaz de compliance pode acabar por antecipar ou mesmo produzir uma imputação que de outra forma não seria revelada ou descoberta pelas autoridades públicas. Outro motivo de rechaço são os custos para a implementação dos procedimentos [...] (BOTTINI, 2016c, p. 55, grifo nosso).
\end{abstract}

É inconteste que o princípio nemo tenetur se detegere pode ser considerado um dos temas mais importantes na colheita da prova direcionada ao processo penal, com vistas à reconstrução dos fatos. Tal princípio constitui um direito fundamental em favor do investigado ou acusado que lhe garante o direito ao silêncio ou, em outras palavras, impede que autoridades imponham a obrigação de se prestar informações contra si mesmo.

Tal princípio, considerado um direito à autodefesa negativa, encontra-se gizado no art. $8^{\circ}, 2$, g, da Convenção Americana de Direitos Humanos e no art. 14, 3, g, do Pacto Internacional de Direitos Civis e Políticos, bem como no art. 5 , LXIII, da CF. Tal princípio, interpretado em conjunto com o princípio da inocência ou da não culpabilidade, permite estender a compreensão de que o silêncio não poderá ser interpretado em prejuízo à defesa.

Segundo Bacigalupo (2005, p. 69, tradução nossa), “[...] o Estado é o fiador de que o suspeito não se incriminará contra a sua vontade, porque a lei atual impõe às autoridades que investigam crimes o dever de instruir qualquer pessoa que seja interrogada”12.

\footnotetext{
12 “[...] el Estado es garante de que el sospechoso no se incrimine contra su voluntad pues el Derecho vigente impone a las autoridades de persecución del delito el deber de instruir a cualquier persona que es interrogada.”
} 
O direito à livre manifestação do acusado pode ser verificado em dupla dimensão: i) uma positiva, referente ao direito irrestrito de declaração em favor de sua defesa sobre os fatos que lhe são imputados; ii) e outra negativa, consistente na vedação de obtenção, por meio enganoso ou por coação, de declarações autoincriminatórias (nemo tenetur se ipsum accusare) (ANDRADE, 2013).

No direito comparado encontramos de forma clara e inconteste da obrigação de que o Estado informe oportunamente o direito ao silêncio, principalmente no momento da prisão, e sua aplicação como corolário de um processo justo e racional contra ação abusiva de autoridades, in verbis:

O direito norte-americano prevê semelhante exigência desde o célebre julgado Miranda $v$. Arizona, em 1966, no qual a Suprema Corte interpretou a $5^{\text {a }}$ Emenda no sentido de que todo suspeito, ao ser inquirido pela polícia, devia ser informado da possibilidade de permanecer em silêncio, de que tudo o que disser ou fizer pode ser usado contra ele, bem como de contar com a assistência de advogado escolhido ou nomeado. No referido julgamento a Suprema Corte entendeu que a ausência da formalidade seria suficiente para macular com o vício da nulidade as declarações feitas. O direito à informação sobre garantia do silêncio ficou conhecido como Miranda's rights e deve ser lido ao suspeito no momento da custódia.

$\mathrm{Na}$ Europa entende-se o direito à não autoincriminação como garantia implicitamente constante no art. $6^{\circ}$, $\S 1^{\circ}$, da Convenção Europeia de Direitos Humanos, por força do caso Saunders v. United Kingdom. No presente caso, a Corte entendeu que, embora não especificamente mencionado no art. $6^{\circ}$ da Convenção, o direito ao silêncio e o direito a não se autoincriminar são geralmente reconhecidos como padrões internacionais que residem no centro da noção de processo justo nos termos do art. $6^{\circ}$. Sua racionalidade reside na proteção do acusado contra uma coação imprópria das autoridades (NARDELLI, 2015).

O direito ao silêncio “[...] é baseado historicamente na rejeição ao autoritarismo, métodos escusos de investigação criminal e, consequentemente, representa a vitória da liberdade e da justiça sobre a tirania e o despotismo” (ROBERTS; ZUCKERMAN, 2010, p. 538).

A verdade buscada nas investigações públicas ou privadas não é o bem maior do processo e não pode ser obtida às custas de direitos fundamentais ${ }^{13}$, razão pela qual há o direito à não autoincriminação (self-incrimination clause) (NARDELLI, 2015). “O direito processual penal oferece, assim, os procedimentos a serem observados pelo Estado na realização de seu poder punitivo; define as regras através das quais o Estado identifica, detém, condena e aplica a pena àqueles que praticaram crimes.” (DIAS NETO, 1997).

À luz da essência do princípio nemo tenetur se detegere, a posição contrária ao compliance não é substancialmente defensável, na medida em que considera o envolvimento da entidade privada ou de seus dirigentes na prática de ilícitos, distanciando-se da posição de interesse das corporações em gerirem os riscos de eventual persecução penal, por meio do reforço do comportamento ético e

\footnotetext{
${ }^{13}$ Uma definição possível de direitos fundamentais aplicada ao objeto de pesquisa é a seguinte: "Direitos fundamentais são direitos público-subjetivos de pessoas (físicas ou jurídicas), contidos em dispositivos constitucionais e, portanto, que encerram caráter normativo supremo dentro do Estado, tendo como finalidade limitar o exercício do poder estatal em face da liberdade individual.” (DIMOULIS; MARTINS, 2009).
} 
do cumprimento fiel das leis e regulamentos, bem como na apuração e comunicação das irregularidades ocorridas.

A posição dos autores, de que as investigações privadas e as comunicações de crimes às autoridades competentes constituem violação ao princípio nemo tenetur se detegere, promove uma generalização a partir de uma exceção possível, que é o envolvimento dos dirigentes da empresa ou do responsável pelo compliance (compliance officer). Tal posição, igualmente, contraria o entendimento de que os agentes privados também devem colaborar com a prevenção penal em face dos riscos produzidos por sua atividade econômica.

Não se deve perder de visa que um dos objetivos do criminal compliance é justamente a individualização da responsabilização penal, seja dos próprios integrantes da organização, seja de terceiros que com ela se relacionam, devido às suas características preventivas e reativas à ocorrência de infrações.

Em situações específicas e com demonstração de conflito de interesses na apuração ou detecção de ilícitos, as entidades privadas poderão invocar a garantia ao silêncio e à impossibilidade de o Estado lhes exigir conduta direcionada à produção de provas contra elas mesmas, seja às entidades reguladoras da atividade econômica, seja ao Ministério Público.

Eventual sanção administrativa será precedida da concessão de ampla defesa e contraditório, quando será possível invocar o direito ao silêncio. Por conseguinte, a comunicação de crimes não lhes será exigida nos casos em que houver envolvimento dos próprios responsáveis pelo dever de comunicação de crimes. Como possíveis consequências à não colaboração privada nesses casos, não haverá direito a benefícios decorrente do compliance e não haverá impedimento ao processamento penal dos responsáveis pelos crimes cometidos, cuja persecução penal caberá ao Ministério Público.

O Ministério Público, por sua vez, quando destinatário das comunicações de indícios de crimes, deve conduzir-se com estrita observância da ordem jurídica, especialmente dos direitos fundamentais, assegurando dessa forma a correção das apurações privadas e as garantias constitucionais como o direito ao silêncio e o de não exigência da produção de provas contra si mesmo, nas hipóteses cabíveis.

\section{CONCLUSÃO}

Na comunidade internacional, o Estado tem apresentado dificuldades na prevenção de ilícitos econômicos, normalmente acobertados por negócios ocultos e dissimulados, ensejando, cada 
vez mais, a participação das entidades privadas no auxílio à prevenção penal, inclusive como forma de gerenciamento de riscos produzidos por suas atividades.

Nesse contexto, surgem os programas de criminal compliance destinados a prevenir práticas de crimes pelos integrantes das organizações ou por terceiros que com ela se relacionam, a servir como um meio para a comunicação de um delito à autoridade competente e a formar uma cultura ética motivadora de comportamentos desejáveis, os quais podem até produzir vantagens competitivas e melhoria de imagem nas entidades privadas e, em alguns casos, melhorar a produtividade.

A introdução do compliance se dá como uma obrigação, no caso de programas implantados nos sistemas financeiros, ou de forma facultativa, quando os programas são acompanhados de incentivos, benefícios e contrapartidas, como a isenção ou a redução de sanções. No Brasil, a exigência de compliance em normas penais foi introduzida pela legislação que criminalizou a lavagem de dinheiro - a Lei $n^{\circ}$ 9.613/98.

O criminal compliance antilavagem alinha-se à política internacional proposta pelo Grupo de Ação Financeira (GAFI), que considera necessária sua implementação por todos os países integrantes, com vistas à implementação de medidas de gestão de riscos e combate à lavagem de dinheiro, ao financiamento ao terrorismo e a outras ameaças à integridade dos sistemas financeiros.

Por meio do criminal compliance antilavagem, pessoas físicas e jurídicas são obrigadas à identificação de clientes e manutenção de cadastros, ao registro de transações e à comunicação de operações suspeitas ou de determinadas transações financeiras, cuja forma e procedimento são definidos pelos órgãos reguladores ou pelo Conselho de Controle de Atividades Financeiras, de acordo com as características das operações.

Há quem sustente a existência de conflito de interesses na adoção desses programas, e que se trata de produção de prova a cargo do Ministério Público. No entanto, a atividade de compliance está ligada essencialmente à mitigação dos riscos produzidos nas atividades desenvolvidas pelas próprias instituições financeiras, seja em relação aos seus integrantes, seja quanto aos clientes e terceiros com quem elas se relacionam. Não há essencialmente interesses contrapostos entre aqueles que buscam o regular exercício de suas atividades e muito menos em face do Ministério Público, instituição que possui dever objetivo de realização da justiça a bem da sociedade, com a garantia dos direitos individuais dos envolvidos.

Por outro ângulo, a reflexão proposta também diz respeito à observância dos direitos fundamentais durante as investigações privadas, especialmente o direito ao silêncio e o de não produzir prova contra si mesmo (nemo tenetur detegere). Não se pode olvidar que a instituição do compliance deveu-se principalmente pela incapacidade fiscalizatória do Estado em todos os 
ambientes econômicos e corporativos, e pelo interesse mútuo, do Estado e das instituições privadas, em reduzir riscos de ocorrência de delitos e facilitar a identificação de eventuais responsáveis, inclusive com a comunicação de crimes, não obstante estejam fixadas obrigações às instituições financeiras na lei de lavagem de dinheiro.

Não se pode dizer que todo o programa de criminal compliance é inconstitucional por ferir o direito ao silêncio e o princípio da vedação de exigência de produção de prova contra si mesmo, pois nem sempre os responsáveis pelo programa (compliance officers) ou os responsáveis pelas organizações são os que apresentam conduta ilícita. Nesse caso, a comunicação de crime não seria exigível e oportunamente pode ser informado o conflito de interesses caso a aplicação de penalidade administrativa por sua omissão tenha curso pelos órgãos reguladores.

Poderá haver discussão sobre coautoria ou participação desses agentes pela omissão imprópria, cujo ônus probatório caberia ao Ministério Público, mas isso não foi objeto específico desse artigo, por envolver marcos teóricos diversos do direito ao silêncio.

Em verdade, como regra, nos casos de inobservância de lei e regulamentos, haverá a individualização da responsabilização penal quando possível, seja dos próprios integrantes da organização ou de terceiros que com ela se relacionam, por sua própria natureza preventiva e reativa à ocorrência de infrações, por meio de investigação privada no âmbito dos programas de criminal compliance, e cujas evidências de crimes, se existirem, serão encaminhadas ao Ministério Público.

Em todos os casos, as investigações desenvolvidas no âmbito do programa de compliance, cuja natureza em princípio é privada, devem atentar aos direitos e garantias constitucionais, em especial o direito ao silêncio (princípio nemo tenetur se detegere), a fim de preservar a licitude das provas, uma vez que suas conclusões podem ser utilizadas em um processo penal, sendo certo que nele são inadmissíveis as provas obtidas por meios ilícitos ${ }^{14}$.

O Ministério Público deve assegurar a correção das apurações privadas nos programas de compliance e as garantias constitucionais nas hipóteses cabíveis, atuando como fiscal da ordem jurídica e exercendo o dever objetivo de realização da justiça, sem atribuir interesse necessariamente contraposto aos investigados.

\footnotetext{
${ }^{14}$ Art. 50, LVI, da CF.
} 


\section{REFERÊNCIAS}

ANDRADE, M. D. C. Sobre as proibições de prova em processo penal. Coimbra: Coimbra, 2013.

ANTUNES, Maria João. Direito Processual Penal. Coimbra: Almedina, 1998.

BACIgAlupo, E. El debido Proceso Penal. Buenos Aires: Hammurabi, 2005.

BECK, U. Sociedade de risco: rumo a uma outra modernidade. Tradução Sebastião Nascimento. São Paulo: 34, 2010. 368 p.

BECKER, G. S. Crime and Punishment: An Economic Approach. Journal of Political Economics, p. 169-217, 1968.

BOTTINI, P. C. Aspectos Conceituais da Lavagem de Dinheiro. In: BOTTINI, P. C.; BADARÓ, G. H. Lavagem de Dinheiro: Aspectos penais e processuais penais. 3. ed. São Paulo: Editora Revista dos Tribunais, 2016a.

BOTTINI, P. C. Políticas de Combate à Lavagem de Dinheiro. In: BOTTINI, P. C.; BADARÓ, G. H. Lavagem de Dinheiro: Aspectos Penais e Processuais Penais. 3. ed. [São Paulo]: Editora Revista dos Tribunais, 2016b.

BOTTINI, P. C. Programas de compliance voltados à prevenção da lavagem de dinheiro. In: BOTTINI, P. C.; BADARÓ, G. H. Lavagem de dinheiro: Aspectos penais e processuais penais. 3. ed. São Paulo: Editora Revista dos Tribunais, 2016c.

BRASIL. Legislação e Normas Antilavagem. Disponível em: https://bit.ly/2TkjQHt. Acesso em: 10 jun. 2018.

CORDERO, I. B. El delito de blanqueo de capitales. Navarra: Arazandi, 2002.

DE CARLI, Carla Veríssimo. Lavagem de dinheiro: ideologia da criminalização e análise do discurso. Porto Alegre: Verbo Jurídico, 2012.

DIAS NETO, T. O Direito ao Silêncio: Tratamento nos direitos alemão e norte-americano. Revista Brasileira de Ciências Criminais, v. 19, p. 179-204, jul-set 1997.

DIMOULIS, D.; MARTINS, L. Teoria geral dos direitos fundamentais. 2. ed. São Paulo: Editora Revista dos Tribunais, 2009.

FERREIRA, M. C. D. Curso de Processo Penal. V. 1. Lisboa: Danúbio, 1986.

GLOECKNER, R. J.; DA SILVA, D. L. Criminal Compliance, Controle e Lógica Atuarial: A relativização do nemo tenetur se detegere. Revista de Direito da Universidade de Brasília, Brasília, v. 1, n. 1, p. 147-172, janeiro-junho 2014.

LIMA, C. F. D. S. Sistema Nacional Antilavagem de Dinheiro: as obrigações de compliance. In: DE CARLI, Carla Veríssimo. Lavagem de Dinheiro: prevenção e controle penal. 2. ed. Porto Alegre: Verbo Jurídico, 2013. 
LIMA, C. F. D. S.; MARTINEZ, André Almeida Rodrigues. Compliance Bancário: um manual descomplicado. São Paulo: Quartier Latin, 2018.

MANZI, Vanessa Alesi. Compliance no Brasil: consolidação e perspectivas. São Paulo: Saint Paul, 2008.

MARTINS JUNIOR, W. P. Ministério Público: A constituição e as leis orgânicas. São Paulo: Atlas, 2015.

NARDELLI, M. A. M. O direito à prova e à não autoincriminação em uma perspectiva comparada entre os processos civil e penal. Revista de Processo, v. 246, agosto 2015.

REINO UNIDO. The Bribery Act 2010: Guidance about procedures which relevant commercial organisations can put into place to prevent persons associated with them from bribing. Disponível em: https://bit.ly/1U6pHxi. Acesso em: 10 jun. 2018.

RIBEIRO, D. C. Ministério Público: dimensão constitucional e repercussão no processo penal. São Paulo: Saraiva, 2003.

ROBERTS, P.; ZUCKERMAN, A. Criminal Evidence. 2. ed. Oxford: Oxford University Press, 2010.

ROXIN, C. Derecho Penal. Parte General. V. I. 2. ed. Madrid: Thomson/Civitas, 2006.

ROXIN, C. Derecho procesal penal. Tradução Gabriela E. Córdoba e Daniel R. Pastor. Buenos Aires: Editores del Puerto, 2000.

ROXIN, C. Posición jurídica y tareas futuras del Ministerio Público. In: VV.AA. El Ministerio Público en el proceso penal. Tradução Julio B. J. Maier. Buenos Aires: Ad Hoc, 1993. Primeira reimpresión, 2000.

SAAVEDRA, Giovani Agostini. Compliance Criminal: Revisão Teórica e Esboço de uma Delimitação Conceitual. Revista Duc In Altum. Cadernos de Direito, vol. 8, no 15, mai-ago. 2016, p. 239-256.

SIEBER, Ulrich. Programas de “compliance” em el Derecho Penal de la empresa: Una nueva concepción para contorlar la criminalidad económica. In: OLAECHEA, José Urquizo; VÁSQUEZ, Manuel Abanto; TIEDEMANN, Klaus; SÁNCHEZ, Nelson Salazar. Homenaje a Klaus

Tiedemann. Dogmática penal de Derecho penal económico y política criminal. V. 1. Lima: Fondo, 2001.

VERÍSSIMO, Carla. Compliance: incentivo à adoção de medidas anticorrupção. São Paulo: Saraiva, 2017.

VIEIRA, V. L. R. A atuação do COAF na prevenção à lavagem de dinheiro à luz da Teoria da Regulação Responsiva. Revista de Direito Setorial e Regulatório, Brasília, v. 4, p. 263-288, maio 2018.

WELTER, C. Dos Crimes: dogmática básica. In: DE CARLI, Carla Veríssimo. Lavagem de Dinheiro: Prevenção e Controle Penal. 2. ed. Porto Alegre: Verbo Jurídico, 2013, cap. 5. 
YSLA, A. C. Legal compliance: Princípios de cumplimiento generalmente aceptados. Madrid: Difusion Juridica, 2012.

Lauro Pinto Cardoso Neto

Procurador Regional da República com atuação na área criminal. Possui graduação em Direito - Associação de Ensino Unificado no Distrito Federal (1998) - e é formado pela Academia Militar das Agulhas Negras (1989). Possui especialização em “Ordem Jurídica e Ministério Público” pela Fundação Superior Escola do Ministério Público do Distrito Federal e Territórios (2002). Mestrando em Direito pela Universidade Católica de Brasília. Dentre outras funções, foi Secretário-Geral do Ministério Público Federal (2010-2016) e participou como membro dos Conselhos Deliberativo e Fiscal da Fundação de Previdência Complementar do Servidor Público do Poder Judiciário (Funpresp-Jud). Possui experiência na área de Direito, Gestão Pública e Defesa. E-mail: laurocardosofe@gmail.com

Nefi Cordeiro Possui graduação em Direito pela Faculdade de Direito de Curitiba (1988), graduação em Engenharia pela Pontifícia Universidade Católica do Paraná (1998), graduação em Oficial Militar pela Academia Policial Militar do Guatupê (1983), mestrado em Direito pela Universidade Federal do Paraná (1995) e doutorado em Direito pela Universidade Federal do Paraná (2000). Atualmente é Ministro do Superior Tribunal de Justiça (STJ), na $6^{\text {a }}$ turma (matéria criminal). Tem experiência na área de Direito Público, com ênfase em Direito Penal, Processual Penal e mediação, atuando principalmente nos seguintes temas: processo, processo penal, prova, penas, contraditório, lavagem de dinheiro e crimes financeiros. É professor universitário na graduação e pós-graduação. Na pós-graduação stricto sensu atua na Universidade Católica de Brasília, na linha de pesquisa Direito, Desenvolvimento e Análise Econômica. E-mail: nefi.cordeiro@msn.com

José Eduardo Sabo Paes Possui graduação em Direito pela Universidade de Brasília (1985), mestrado em Magister en Derecho Comparado pela Universidad Complutense de Madrid (1996) e doutorado em Direito Constitucional pela Universidad Complutense de Madrid (1997), reconhecido pela UFPE. Atualmente é professor da Universidade Católica de Brasília e procurador de justiça do Ministério Público do Distrito Federal e Territórios. Tem experiência na área de Direito Constitucional, Terceiro Setor, Fundações, Direitos Fundamentais Individuais e Coletivos, Código Civil e Ministério Público. Atua nas seguintes linhas de pesquisa: Direito, Estado, Tributação e Desenvolvimento; Sociedade, Terceiro Setor, Ordem Internacional e Direito; Terceiro Setor e Tributação: parcerias público-privadas, suspensão das imunidades e holdings no Terceiro Setor. E-mail: eduardosabo3@gmail.com 